\title{
Coronavirus Disease 2019 (COVID-19) Mechanical Ventilation Research Theme Analysis: Co-word Cluster Analysis
}

\author{
Hongyan Chen, Xiaoyi Huang, Siyi Chen, Wenjing Zhu, Wentao Huang and Ken Chen \\ School of Nursing, Guangdong Pharmaceutical University, China
}

\begin{abstract}
The objective of this analysis was to explore the research hotspot of coronavirus disease 2019 (COVID-19) mechanical ventilation. The literature related to COVID-19 mechanical ventilation on PubMed and CNKI database of core journals was retrieved with the keyword of COVID-19 mechanical ventilation. The visualisation software of VOS (visualisation of similarities) viewer performed by the authors and high-frequency keywords. A total of 524 English language articles from PubMed and 81 Chinese literature from China National Knowledge Infrastructure (CNKI) of core journals are included in this paper. The two databases produced six research fields, among which much attention was paid to the prevention of nosocomial infection and antiviral agents in the treatment of mechanical ventilation. The literature yeilded by PubMed paid attention to the factors affecting the poor prognosis of mechanically ventilated patients, the management and research and development of medical data during COVID-19's pandemic, the mechanical ventilation treatment of COVID-19 pregnant women, the mechanical ventilation treatment and nursing in the field of CNKI literature research, and the nutritional treatment of severe pneumonia patients with mechanical ventilation. The current COVID-19 researches, focused on the prevention of nosocomial infection and antiviral drugs in the process of mechanical ventilation, are a new hotspot in the world.
\end{abstract}

Key Words: Coronavirus disease 2019 (COVID-19), Mechanical ventilation, Research hotspot, VOSviewer, Visual analysis.

How to cite this article: Chen H, Huang X, Chen S, Zhu W, Huang W, Chen K. Coronavirus Disease 2019 (COVID-19) Mechanical Ventilation Research Theme Analysis: Co-word Cluster Analysis. J Coll Physicians Surg Pak 2020; 30(JCPSPCR):CR94-CR100.

\section{INTRODUCTION}

Since December 2019, a global outbreak of virus infection has spread all over the world. The disease caused by this virus infection is called coronavirus disease 2019 (COVID-19). ${ }^{1}$ The number of infected cases is increasing rapidly as well as the deaths. More than 4.3 million people worldwide have been infected, with a cumulative global death toll of more than 290,000 and a global mortality rate of $6.85 \% .{ }^{2}$ COVID-19 has brought a heavy burden to the world because of its severe respiratory failure. Among the infected, $3 \%$ of patients will develop into severe cases, and the proportion of critical COVID-19 patients receiving endotracheal intubation varies between $16.75-57 \%$, requiring invasive mechanical ventilation..$^{3-5}$

VOSviewer is a visualisation software developed by Dr. Jie Li's team. It not only assists in the analysis of essential knowledge, but also helps for focusing on hotspots in scientific research.

Correspondence to: Ken Chen, School of Nursing, Guangdong Pharmaceutical University, 283 Jianghai Avenue, Haizhu District, Guangzhou 510000, China

E-mail: cc673626220@163.com

Received: July 07, 2020; Revised: August 20, 2020;

Accepted: September 08, 2020

DOI: https://doi.org/10.29271/jcpsp.2020.JCPSPCR.CR94
Since the outbreak of the epidemic, researches on COVID-19 have been increasing. At present, some researches have analysed COVID-19 related literatures, ${ }^{6-8}$ but articles about COVID-19 mechanical ventilation have not been published. The unified global guidelines for the management of mechanical ventilation need to be continuously updated. Consequently, there is an urgent need to analyse the current situation and research direction of mechanical ventilation treatment of COVID-19 patients, ${ }^{9}$ in order to provide ideas for global COVID-19 mechanical ventilation research.

\section{METHODOLOGY}

Chinese (China National Knowledge Infrastructure: CNKI) and English (PubMed) databases were searched to obtain relevant periodical literatures. Firstly, we collected data from the CNKI database by using advanced search types, with title and subject as search items, and we limited our search to the following keywords, such as coronavirus disease 2019 (COVID-19), COVID-19, COVID19, SARS-COV-2, NCP (novel coronavirus pneumonia), mechanical ventilation, endotracheal intubation or tracheotomy. Next, a comprehensive search was conducted using PubMed database to identify manuscripts with the following search strategy: subject as search item, the literature type as article and review; and the keywords COVID-19 mechanical ventilation, cairway manage- 
ment, and corresponding sub-subject words. The time range of literature retrieval started from January 1, 2020, till May 15, 2020. All documents in the CNKI database contained English abstracts.

VOSviewer software is a bibliometrics visualisation software, developed in Java language. Its main functions are scientific research network co-author analysis, subject analysis, and domain contribution analysis. VOSviewer software was used to build keyword network analysis view and author network analysis view, the larger the node, the higher the frequency; the more the number of connected nodes, the more reliable was the keyword or topic connection. Then the research hotspots of the authorand keywords were analysed, respectively.

\section{RESULTS}

From 2020-01 to 2020-05, a total of 570 PubMed articles met the above search criteria, while 524 articles were included after excluding the 92 duplicate articles. A total of 141 CNKI articles met the above search criteria, among which we removed 21 inappropriate English articles, five unauthoredarticles, sixunrelated articles and 28 articles that published in other languages; and the rest of 81 articles were included for analysis.

PubMed and CNKI generate 1,112 and 159 keywords, respectively. We combined the keywords with the same meaning to get the keyword co-occurrence frequency table and the top 16 keywords in the two databases (Table I). Manuscripts from both PubMed and CNKI were concerned with the personal protection of viral epidemics, mechanical ventilation, and severe pneumonia. Publications from PubMed also paid attention to elderly COVID-19 patients, while CNKI paid attention to extracorporeal life-support care, such as extracorporeal membrane oxygenation.

Among the literature related to COVID-19 mechanical ventilation included in PUBMED database, there were 1,112 keywords and 82 high-frequency keywords with a frequency of more than five times, which was considered a new research hotspot in the past five months. Moreover, six clusters identified by cluster analysis (Table II, Figure 1). The first type was red, which mainly studied the effect of aerosol generated by endotracheal intubation or tracheotomy on the infection of medical staff in the intensive care unit. Researchers developed practical guidelines for the prevention and control of viral infections in surgical anesthesia, airway management, and personal protection. The second category was green, which mainly studied the influencing factors of treatment outcome and prognosis of elderly patients with COVID-19, and discusses the risk factors that affect prognosis. The third and sixth clusters were purple and yellow, respectively. The main research contents included the management and allocation of medical resources (medical masks, N95 masks, ventilators), during public health emergencies and pandemics. The fourth group mainly studied the antiviral treatment of acute respiratory distress syndrome caused by viral pneumonia. The fifth group mainly studied the treatment of hypopnea in severe pregnant women and postpartum treatment of newborns.
Among the literatures related to COVID-19 airway management included in the CNKI database, 159 keywords were generated, of which 39 appeared more than twice, which is a research hotspot in this field. Nine clusters were determined by cluster analysis of the first 39 keywords (Figure 2). Among the first six clusters, the first cluster was red, and the main content is to find the best evidence of infection protection measures for newborns and children through systematic evaluation. The second group was the green group, which mainly studies the nutritional treatment of mechanically ventilated severe pneumonia patients with different clinical characteristics. The third group's theme repeated with the sixth group, which were blue and purple, respectively, and mainly discussed the mechanical ventilation oxygen therapy for critically ill patients. The fourth group was yellow, which studied the infection prevention measures and drug treatment of medical staff during mechanical ventilation treatment. The fifth group mainly discussed the nursing care of intensive care patients using extracorporeal lung membrane oxygenation and other extracorporeal life support.

PubMed produced a total of 3,108 authors, and the author co-citation analysis is visualised in Figure 3. Twelve teams were found in this figure, and in some teams more than two members were included. Among them, Carratalperales and Jose Manuel is the largest team with a maximum output of 2 articles, followed by Akkanti, Bindu, and Mariann team with a maximum output of 3 articles.

CNKI produced a total of 607 authors. There were six teams with more than two authors. Of which, Jianying Zhou's team was the largest and one of the most prolific teams, followed by Xin Liu 's side, the highest author output is 2, the third is Zhang Wei's team, and the author's highest outputis three articles.

\section{DISCUSSION}

Severe COVID-19 patients rapidly develop into acute respiratory distress syndrome. Active clinical treatment aims to improve hypoxemia and reduce complications and mortality. At present, severe COVID-19 acute respiratory distress syndrome is mainly treated by endotracheal intubation, tracheostomy, non-invasive, or invasive positive pressure mechanical ventilation, and $5 \%$ of patients need extracorporeal membrane oxygenation. With the continuous improvement of the understanding of COVID-19 and severe COVID-19, the research on COVID-19 airway management is increasing, so it is necessary to systematically analyse its knowledge structure and research topics.

The theme of the first group of PubMed was similar to that of the fourth group of CNKI to study the prevention and treatment of secretion infection caused by mechanical ventilation in critically ill COVID-19 patients. The main research of its object was aerosol. Aerosols may be generated by endotracheal intubation or mechanical ventilation, so protective measures should be taken, and quantitative inhalation therapy should be used instead of atomisation therapy, because positive pressure ventilation may increase the risk of infection in medical workers. ${ }^{10,11}$ 
Table I: PubMed and CNKI keywords frequency table.

\begin{tabular}{|l|l|l|l|l|}
\hline \multirow{2}{*}{ Ranking } & PubMed & \multicolumn{2}{l|}{ CNKI } \\
\cline { 2 - 5 } & Keywords & Frequency & Keywords \\
\hline 2 & COVID-19 & 343 & COVID-19 & 72 \\
\hline 3 & Pandemic & 136 & ECMO & 16 \\
\hline 4 & Pneumonia, Viral & 125 & ARDS & 8 \\
\hline 5 & Human & 124 & Critical illness & 8 \\
\hline 6 & Beta-coronavirus & 104 & Mechanical ventilation \\
\hline 7 & Coronavirus & 87 & Nursing & 7 \\
\hline 8 & Mechanical ventilation & 39 & Respiratory therapy technology \\
\hline 9 & PPE & 36 & Tracheal intubation \\
\hline 10 & Male & 31 & High-flow nasal cannula oxygen therapy & 7 \\
\hline 11 & China & 27 & Protection measure \\
\hline 12 & Intensive care & 27 & Tracheotomy \\
\hline 13 & Female & 26 & Clinical characteristics \\
\hline 14 & Infection control & 26 & Epidemiology \\
\hline 15 & Middle-aged & 26 & Infection control \\
\hline 16 & Tracheostomy & 26 & Intensive care \\
\hline
\end{tabular}

COVID-19: Coronavirus Disease 2019; ECMO: Extracorporeal membranous oxygenation; ARDS: Acute respiratory distress syndrome; PPE: Personal protective equipment.

Table II: PubMed and CNKI keywords clustering table.

\begin{tabular}{|c|c|c|c|c|}
\hline \multirow[b]{2}{*}{ Cluster } & \multicolumn{2}{|l|}{ PubMed } & \multicolumn{2}{|l|}{ CNKI } \\
\hline & $\begin{array}{l}\text { No. of } \\
\text { frequency }\end{array}$ & Keywords & $\begin{array}{l}\text { No. of } \\
\text { frequency }\end{array}$ & Keywords \\
\hline 1 & $\begin{array}{l}1,6,8,13,15,17 \\
20,21,22,28,37 \\
39,43,45,47,51 \\
58,60,62,66,69 \\
74,79\end{array}$ & $\begin{array}{l}\text { COVID-19, coronaviru, personal protective equipment (PPE), } \\
\text { infection control, tracheostomy, airway management, ARDS, } \\
\text { tracheal intubation infection disease transmission, patient-to- } \\
\text { professional, respiratory insufficiency, aerosols, intubation, } \\
\text { tracheotomy, airway, coronavirus infection, safety, infection, } \\
\text { pregnancy, Transmission, infection prevention and control, } \\
\text { otolaryngology, anaesthesia, guideline }\end{array}$ & $\begin{array}{l}11,16,17 \\
18,26,33 \\
34,36\end{array}$ & $\begin{array}{l}\text { Tracheotomy, pneumonia, child, } \\
\text { Coronaviru, newborn, protective measure, } \\
\text { severe acute respiratory syndrome (ARDS), } \\
\text { systematic review }\end{array}$ \\
\hline 2 & $\begin{array}{l}9,10,12,14,16 \\
19,25,31,32,33 \\
38,42,48,53,54 \\
55,56,70,72,76 \\
77\end{array}$ & $\begin{array}{l}\text { Male, China, female, middle aged, adult Aged, clinical } \\
\text { laboratory technique, retrospective study, risk factor, severity } \\
\text { of illness index, child, radiography, thoracic, fever, treatment } \\
\text { outcome, young adult, adolescent, aged, } 80 \text { and over, } \\
\text { prognosis, time factor, cough, diarrhea }\end{array}$ & $\begin{array}{l}12,13,19 \\
20,29,35\end{array}$ & $\begin{array}{l}\text { Clinical characteristics, epidemiology, } \\
\text { critical type, enteral nutrition, nutrition } \\
\text { therapy, severe pneumonia }\end{array}$ \\
\hline 3 & $\begin{array}{l}2,3,4,7,11,26 \\
30,41,44,50,61 \\
65,67,75,81\end{array}$ & $\begin{array}{l}\text { Pandemic, pneumonia, viral, human mechanical ventilation, } \\
\text { intensive care, disease outbreak, infection disease, public } \\
\text { health, ventilators, mechanical, resource }\end{array}$ & $\begin{array}{l}1,5,7,9 \\
14,27\end{array}$ & $\begin{array}{l}\text { COVID-19, mechanical ventilation, } \\
\text { respiratory therapy technology, high-flow } \\
\text { nasal cannula oxygen therapy, infection } \\
\text { control, non-invasive positive pressure } \\
\text { ventilation }\end{array}$ \\
\hline 4 & $\begin{array}{l}24,27,35,49,52 \\
57,64,68,71\end{array}$ & $\begin{array}{l}\text { intensive care unit (ICU), pneumonia, mask, hospitalization, } \\
\text { treatment, epidemiology, cytokine storm }\end{array}$ & $\begin{array}{l}4,10,24 \\
25,31,37\end{array}$ & $\begin{array}{l}\text { Critical illness, protection measure, } \\
\text { infection, intensive care medicine, } \\
\text { personal protection, ventilator }\end{array}$ \\
\hline 5 & $\begin{array}{l}5,23,34,36,46 \\
59,63,73,82\end{array}$ & $\begin{array}{l}\text { Beta-coronavirus, SARS, lung, respiratory distress syndrome, } \\
\text { adult, animal, inflammation }\end{array}$ & $\begin{array}{l}2,6,15 \\
21\end{array}$ & $\begin{array}{l}\text { Extracorporeal membranous oxygenation } \\
\text { (ECMO), nursing, intensive care, } \\
\text { extracorporeal life support }\end{array}$ \\
\hline 6 & $18,29,40,78,80$ & $\begin{array}{l}\text { Extracorporeal membrane oxygenation, critical illness, practice } \\
\text { guideline as topic, emergency service, hospital, hypoxia }\end{array}$ & $22,23,28$ & $\begin{array}{l}\text { Hyperbaric oxygen, hypoxemia, } \\
\text { nosocomial infection }\end{array}$ \\
\hline
\end{tabular}

The Praveen team studied the transport of COVID-19 patients with endotracheal intubation and mechanical ventilation. The results showed improved success rate of intubation, depended on the experience and skilled operation team, and it was recommended that men and women should use 8.0 $\mathrm{mm}$ and $7.5 \mathrm{~mm}$ cathetor, respectively. In addition, to reduce infection, mechanical ventilation, or atomisation is not recommended during transport. ${ }^{12}$ The use of aerosol boxes for intubation may increase intubation time and the risk of infection. ${ }^{13}$ However, some studies have shown that endotracheal intubation box may bring benefits, and the study of endotracheal intubation box may improve the success rate of endotracheal intubation; and reduce the infection of medical staff. ${ }^{14}$ Moreover, Medical personnel must be provided adequate and effective personal protective equipment during endotracheal intubation or nursing, such as powered air purification respirators (PAPRs). ${ }^{15}$ Khoury invented an airway nega- tive pressure respirator (NAPR) that can effectively prevent aerosol spills, thereby protecting medical staff. ${ }^{16}$

It is worth mentioning that the risk of infection caused by extubation, using two airway filters during extubation, can reduce the risk of infection. ${ }^{17}$ Healthcare facilities providers are advised to use electronic intensive care unit (E-ICU) systems to reduce healthcare workers infections. ${ }^{18}$ Virus RNA exists in different areas of the hospital, and its infectivity cannot be determined, but the number of viruses has been reduced after strict disinfection. Therefore, it recommended that all parts of the hospital should be disinfected regularly, and the wards should be ventilated. ${ }^{19}$

The first major content of the CNKI research was to systematically review and find the best evidence for preventive measures to prevent infections in newborns and children, including neonatal COVID-19's diagnosis, transportation 
management, infection control, and discharge plan. ${ }^{20,21}$ The humoral management of children with potential heart disease is also the focus of attention. ${ }^{22}$

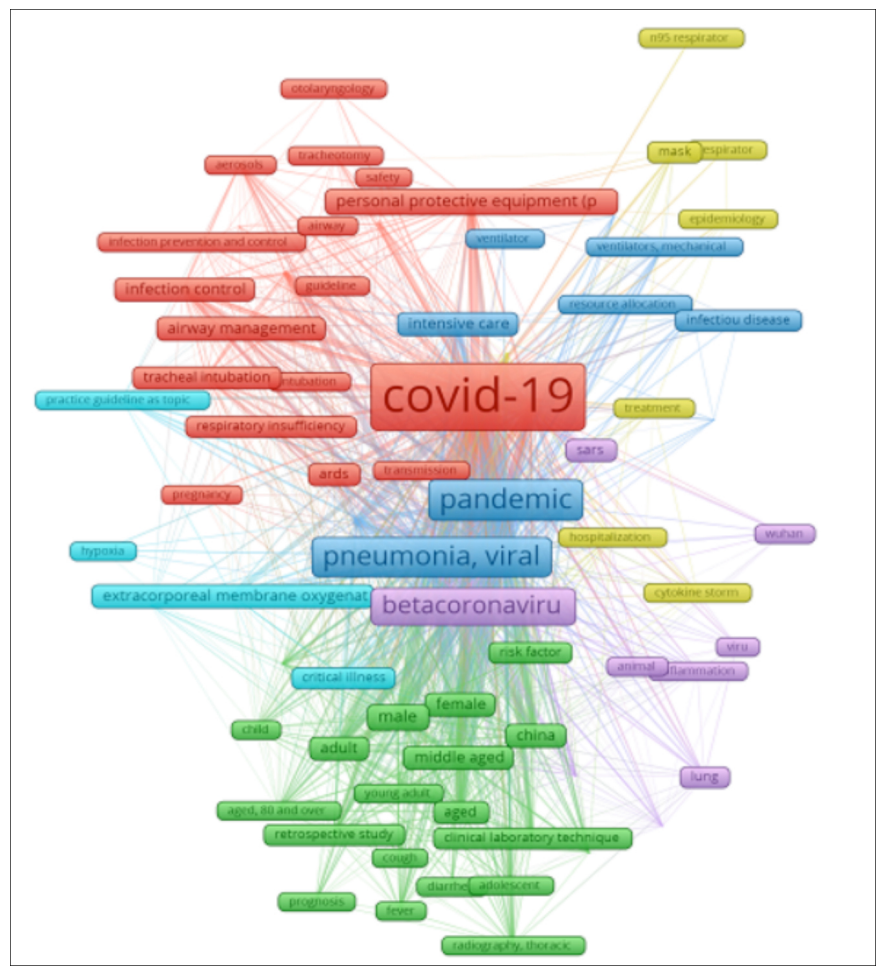

Figure 1: PubMed keyword co-occurrence visualisation diagram.

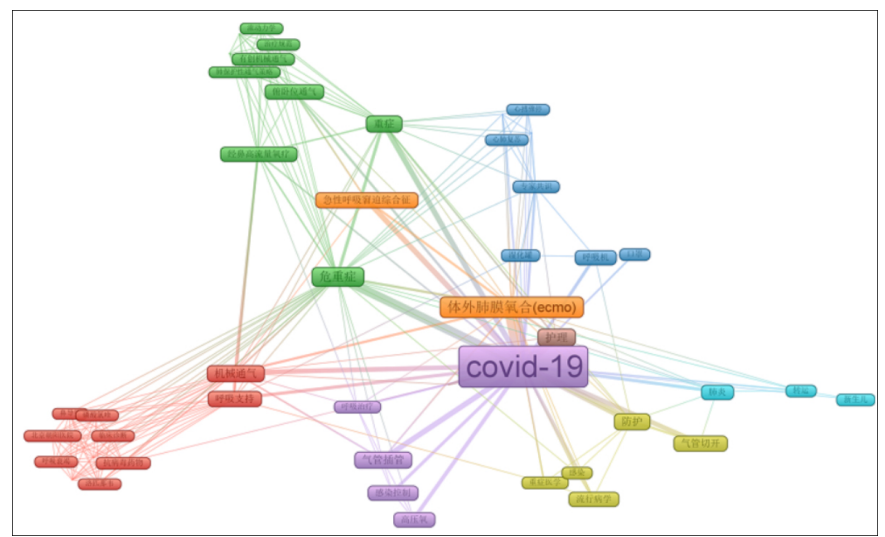

Figure 2: CNKI keyword co-occurrence visualisation chart.

The second group of PubMed mainly discussed the risk factors affecting the prognosis of COVID-19 patients with mechanical ventilation. Most studies have shown that high sequential organ failure assessment (SOFA) score, d-dimer $>1 \mu \mathrm{g} / \mathrm{mL}$, and elevated procalcitonin level are risk factors for poor prognosis in elderly patients with sequential organ failure. D-dimer $>1 \mu \mathrm{g} / \mathrm{mL}$ and elevated procalcitonin level can be used as warnings of poor prognosis. ${ }^{5,23}$

The second group of CNKI mainly studied the nutritional treatment of severe pneumonia patients with different clinical features. Yu Wang and other researchers found that nutritional support therapy was the primary source of nutrition for mechanically ventilated patients. Different nutri- tional strategies for patients with different conditions. Nearly $90 \%$ of critically ill patients have an NRS2002 score of more than 5 , so the professional dietitians are needed to formulate treatment plans, and the priority is given to enteral nutrition with high energy density, and the use of insulin pump to control blood sugar. ${ }^{21}$ However, previous study found that the incidence of gastrointestinal adverse reactions in critically ill patients is very high, and it is recommended to use parenteral nutrition as much as possible, which is contrary to the recommendations of expert guidelines. ${ }^{24,25}$ Therefore, nutritional support therapy is essential, and appropriate nutritional treatment can improve the prognosis of patients.

PubMed clusters 3 and 6 mainly covered the management, production, and use of medical resources (medical masks, N95 masks, ventilators) during public health emergencies and pandemics. At present, the focus was on flexible nanoapertures film masks (aperture less than $5 \mathrm{~nm}$ ), graphene masks (reusable), and powered air purification respirators (PAPRs). ${ }^{26,27}$ Paying attention to the performance of different masks is also the main content of research. The performance of mixed material masks was found to be better. ${ }^{28}$ There was no difference between the use of two masks to prevent infection in air-conditioned rooms and healthy people in the community. ${ }^{29}$

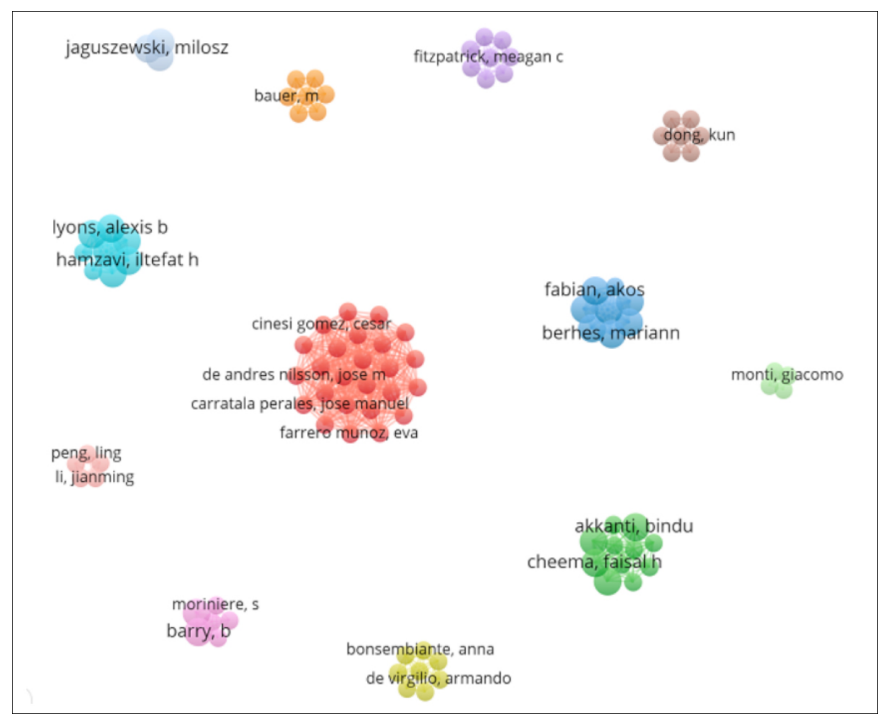

Figure 3: Visualisation of the author's collaboration.

In addition, professionals had difficulty communicating and understanding them during the use of personal protective equipment. ${ }^{30}$

The study of third and sixth groups of studies in CNKI shared the same theme: mechanical ventilation in COVID-19 patients. Based on the treatment experience of critically ill patients, FW Jia and other groups summarised the recommendations and operating rules for endotracheal intubation, determined the indications for invasive mechanical ventilation from the mechanism of lung injury, and discussed issues that should be noted in respiratory support treatment and 
nursing. Timely use of ventilator support (mechanical ventilation, ECMO) that brings greater benefits. The pressure of mechanical ventilation will be adjusted according to the severity of the patient's condition to avoid lung injury, which can be aggravated by blind lung reexpansion. ${ }^{31}$ Besides, many studies have shown that ACE2 (angiotensin-converting enzyme 2) may aggravate acute lung injury. ${ }^{32}$

The fourth group of PubMed data and the fourth group of CNKI studied the efficacy of antiviral therapy. The clinical effectiveness of COVID-19 antiviral agents has always been a contradictory and controversial topic. Some studies have shown that different studies have come to different conclusions.

Six antiviral agents such as arbidol capsule and Lopinavir/ritonavir tablets were not beneficial for critically ill patients. ${ }^{22}$ There was no significant correlation between hydroxychloroquine and intubation or death. ${ }^{6}$ In addition, the use of hydroxychloroquine or chloroquine has no obvious benefit for the treatment of COVID-19, which could reduce the in-hospital survival rate of COVID-19 patients and increase the incidence of ventricular arrhythmias. ${ }^{33}$ There was no significant difference in clinical improvement time between the acyclovir group and the control group. ${ }^{34}$ Lopinavir-ritonavir had no substantial improvement in critically ill patients, and has more adverse reactions,,$^{35}$ a study on the contrary.

Famciclovir can improve the clinic status of ventilation, and remdesivir can improve the symptoms of patients with severe mechanical ventilation. ${ }^{36}$ Antiviral treatments, such as lopinavir/ritonavir, hydroxychloroquine, and ribavirin, can significantly reduce mortality and enhance ventilation. ${ }^{37}$ Peramivir can improve critically ill patients with mechanical ventilation, but it has serious adverse reactions. ${ }^{38}$ Severe patients should give priority to hydroxychloroquine or Lopinavir/ritonavir antiviral therapy. ${ }^{39}$ The efficacy of arbidol and $\mathrm{LPV} / \mathrm{r}$ alone or in combination is also controversial. Favipiravir (FPV) and Lopinavir (LPV) / ritonavir (RTV) treatment of COVID-19 is superior to Favipiravir (FPV) alone in controlling disease progression and shortening virus clearance time. ${ }^{40,41}$ which is inconsistent with the results of ZhenZ. ${ }^{42}$ The above research results need to be verified by large-scale randomised trials.

The fifth group of PubMed data mainly studied the treatment of severe maternal hypoventilation, mainly related to the mechanical ventilation of COVID-19 pregnant women. A cohort study in the United States found that $73 \%$ of severe COVID-19 pregnant women needed oxygen therapy, 95 percent of critically ill women required intubation, 50 percent of critically ill COVID-19 women opted to give birth due to infection, nearly 88 percent of pregnant women gave birth prematurely, ${ }^{43}$ and vaginal delivery had a lower risk of new infections. ${ }^{44}$

The indicators used in previous studies to predict prognosis and disease progression also apply to pregnant women. ${ }^{43}$ Postpartum management of newborns is a potential key research field.

The fifth CNKI data clustering mainly studied the mechanical ventilation, extracorporeal membrane oxygenation, and other extracorporeal life-support nursing in intensive care patients. Extracorporeal membrane lung combined with mechanical ventilation patient transportation care strategies include infection prevention, treatment, pre-, mid-, and post-transport care. ${ }^{44}$ Xin Liu 's team used prone position mechanical ventilation for patients with mechanical ventilation to improve ventilation conditions. At the same time, he also recommended to pay attention to prevent loss of ventilation tubes, skin management, and pneumothorax. ${ }^{45}$ The key to preventing ventilation failure in nursing is to avoid air leakage in the masks. For patients with thinner faces, gauze can be filled between the mask and the skin, and the headband can be loosened to accommodate a finger, nasal bridge, and cheeks on both sides to paste colloidal dressings to prevent pressure damage to the skin. ${ }^{46}$ It is also worth noting that compared to the operational skills of ECMO, the difficulty is the lack of professionals who detect and manage ECMO, so training professionals is the current challenge. ${ }^{47}$

The authors believe that this research can reflect the new direction of COVID-19 mechanical ventilation treatment and provide clues for COVID-19 mechanical ventilation.

\section{CONCLUSION}

The authors and keywords of the literature on COVID-19 mechanical ventilation in PUBMED and CNKI databases were evaluated; and the research hotspots were analysed in the field of COVID-19 mechanical ventilation in the past five months. With the increasing number of patients with acute respiratory distress syndrome, publications from PubMed also paid attention to elderly COVID-19 patients, while CNKI paid attention to extracorporeal life-support care, such as extracorporeal membrane oxygenation. The application of COVID-19 mechanical ventilation in infection prevention, control and antiviral therapy has become the focus of global research. At present, there is a lack of randomised controlled trials.

\section{PATIENTS' CONSENT:}

Patients' consent is not applicable because the present study is a bibliometric analysis.

\section{CONFLICT OF INTEREST:}

Authors declared no conflict of interest.

\section{AUTHORS' CONTRIBUTION:}

$\mathrm{HC}, \mathrm{XH}$ : Designed the study, interpreted data and drafted the manuscript.

SC, WZ, WH: Collected data and edited the manuscript.

KC: Drafted the work and revised it critically for important intellectual content. Agreed to be accountable for all aspects 
of the work.

\section{REFERENCES}

1. Helmy YA, Fawzy M, Elaswad A, Sobieh A, Kenney SP, Shehata AA. The COVID-19 pandemic: A comprehensive review of taxonomy, genetics, epidemiology, diagnosis, treatment, and control. J Clin Med 2020 9(4):1225. doi: $10.3390 / \mathrm{jcm} 9041225$.

2. Coronavirus Disease (COVID-19) Situation Report - 116. World Health Organization.15 May 2020. http://www.who.int/docs/default-source/coronaviruse/situati on-reports/20200515-covid-19-sitrep-116.pdf?sfvrsn=8dd609562.

3. Galleries J, Oshua G, Yifei S, Platt J, Zucker J, Baldwin M, et al. Observational study of hydroxychloroquine in hospitalized patients with Covid-19. N Engl J Med 2020; 382(25):2411-8. doi: 10.1056/NEJMoa2012410.

4. Feng $Y$, Ling Y, Bai T, Xie Y, Huang J, Li J, et al. COVID-19 with different severity: A multi-center study of clinical features. Am J Respir Crit Care Med 2020; 201(11) dol. 10.1164/ rccm.202002-04450C.

5. Zhou F, Yu T, Du R, Fan R, Liu Y, Liu Z, et al. Clinical course and risk factors for mortality of aadult inpatients with COVID-19 in Wuhan, China: A retrospective cohort study. Lancet 2020; 395(10229):1054-62. doi: 10.1016/ S01406736(20)30566-3.

6. Tao Z, Zhou S, Yao R, Wen K, Da W, Meng Y, et al. COVID-19 will stimulate a new coronavirus research breakthrough 20year bibliometric analysis. Ann Transl Med 2020; 8(8):528. doi: 10.21037/atm.2020.04.26.

7. Zhai F, Zhai Y, Cong C, Song T, Xiang R, Feng T, et al. Research progress of coronavirus based on bibliometric analysis. Int J Environ Res Public Health 2020; 17(11):3766. doi: 10.3390/ijerph17113766.

8. Kambhampati SBS, Vaishya R, Vaish A. Unprecedented surge in publications related to COVID-19 in the first three months of a pandemic: A bibliometric analytic report, J Clin Orthop Trauma 2020; 11(Suppl 3):S304-6. doi: 10.1016/j.jcot.2020.04.030.

9. Cook TM, El Boghdadly K, McGuire B, McNarry AFA, Patel A, Higgs $A$. Consensus guidelines for managing the airway in patients with COVID-19: Guidelines from the difficult airway society, the association of anaesthetists the intensive care society, the faculty of intensive care medicine and the royal college of anaesthetists. Anaesthesia 2020; 75(6):785-99. doi: 10.1111/anae.15054.

10. Whittle JS, Pavlov I, Sacchetti AD, Atwood C, Rosenberg MS. Respiratory support for adult patients with COVID-19. J Am Coll Emerg Physicians Open 2020; doi: 10.1002 / emp2. 12071.

11. Feldman O, Meir M, Shavit D, Idelman R, Shavit I. Exposure to a surrogate measure of contamination from simulated patients by emergency department personnel wearing personal protective equipment. JAMA 2020; 323(20): 2091-3. doi: 10.1001/jama.2020.6633.

12. Chahar P, Dugar S, Marciniak D. Airway management considerations in patients with COVID-19. Cleve Clinic J Medicine 2020; doi:10.3949/ccjm.87a.ccc033.
13. Begley JL, Lavery KE, Nickson CP, Brewster DJ. The aerosol box for intubation in COVID-19 patients: An in situ simulation crossover study. Anaesthesia 2020; 75(8):1014-21. doi: 10.1111/anae.15115.

14. Dalli J, Khan MF, Marsh B, Nolan K, Cahill RA. Evaluating intubation boxes for airway management. Br J Anaesth 2020; 125(3):e293-e295. dol. 10.1016/j.bja.2020.05.006.

15. Sommer DD, Engels PT, Weitzel EK, Khalili S, Corsten M, Tewfik MA, et al. Recommendations from the CSO-HNS taskforce on tracheotomy performance during the COVID-19 pandemic. J Otolaryngol Head Neck Surg 2020; 49(1):23. doi: 10.1186/s40463-020-00414-9.

16. Tawfiq Khoury $T$, Lavergne $P$, Chitguppi $C$, Rabinowitz $M$, Nyquist G, Rosen $M$, et al. Aerosolised particle reduction: $A$ novel cadaveric model and a negative airway pressure respirator (NAPR) system to protect health care workers from COVID-19. Otolaryngology-Head and Neck Surgery 2020; 163(1):151-5. doi: 10.1177/0194599820929275.

17. Ryan VW, Endersby, Esther CY, Edward S, Adam OS. Modified tracheal extubation for patients with COVID-19. British J Anaesth 2020; 125(1):e191-2. doi: 10.1016/j.bja. 2020.04.062.

18. Gondal KM, Shaukat S. Telemedicine in the time of COVID-19 pandemic. J Coll Physicians Surg Pak 2020; 30(4):349-50. doi: 10.29271/jcpsp.2020.04.3490.

19. Liu Y, Ning Z, Chen Y, Guo M, Liu Y, Gali NK, et al. Aerodynamic analysis of SARS-CoV-2 in two Wuhan hospitals. Nature 2020; 582(7813):557-60. doi: 10.1038/ s41586020-2271-3.

20. Shalish W, Saty Anarayana L, Paolo M, Martin K, Guilherme M, Sant'Anna. COVID-19 and neonatal respiratory care: Current evidence and practical approach. Am J Perinatol 2020; 37(8):780-91. doi[10.1055/s-0040-1710522.

21. Wang $Y$, Yue XF, Zhang J. Nutritional intervention and pharmaceutical care practice of 39 COVID-19 critically ill patients. Chinese J Hospital Pharmacy http://kns.cnki.net/ kcms/detail/44.1193.R.20200423.1322.002.html

22. Zengyuan $Y$, Xue $W$, Yingjun F. Transport $\square$ diagnosis and treatment of a newborn with severe SARS-CoV-2 infection: A case report. Chinese J Evidence-Based Pediatrics (China) 2020; 15(01):37-41.doi:10.3969/j.issn.1673-5501.2020.01. 009.

23. Du Y, Tu L, Zhu P, Mu M, Wang R, Yang $P$, et al. Clinical features of 85 fatal cases of COVID-19 from Wuhan: A retrospective observational study. Am J Respir Crit Care Med 2020; 201(11):1372-9. doi $10.1164 /$ rccm.202003-05430C.

24. Singer $\mathrm{P}$, Blaserb AR, Berger MM, Alhazzani W, Calder PC, Casaer MP, et al. ESPEN guideline on clinical nutrition in the intensive care unit. Clin Nut 2019; 38(1):48-79. dol. 10.1016/ j.clnu.2018.08.037.

25. Blaser AR, Starkopf J, Alhazzani W, Berger MM, Casaer MP, Deane $A M$, et al. Early enteral nutrition in critically ill patients: ESICM clinical practice guidelines. Intensive Care Med 2017; 43(3): 380-98. DOI: 10.1007/s00134-0164665-0.

26. El-Atab N, Qaiser N, Badghaish HS, Shaikh SF, Hussain MM. Flexible nanoporous template for the design and development of reusable Anti-COVID-19 Hydrophobic face masks. ACS Nano 2020; 14(6):7659-65. doi: 10.1021/acsnano. 
0c03976.

27. Zhong $\mathrm{H}$, Zhu Z, Lin J, Cheung CF, Vivien L Lu, Yan F, et al. Reusable and recyclable graphene masks with outstanding superhydrophobic and photothermal performances. ACS Nano 2020; 14(5):6213-21. doi:10.1021/acsnano.0c02250.

28. Abhiteja K, Abhinav P, Gregory AM, Michael S, Gregory DG, Supratik G. Aerosol filtration efficiency of common fabrics used in respiratory cloth masks. ACS Nano 2020; 14(5):6339-47. doi: 10.1021/acsnano.0c03252.

29. Kin FH, Lian YL, Shao PW, Kai JC. Medical mask versus cotton mask for preventing respiratory droplet transmission in microenvironments. Sci Total Envir 2020; 735:139510. DOI $10.1016 /$ j.scitotenv.2020.139510.

30. Parush A, Wacht O, Gomes R, Frenkel A. Human factors considerations in using personal protective equipment in the COVID-19 pandemic context: A bi-national survey study. J Med Int Res doi: 10.2196/19947.

31. Jiafang W, Fan L, Mingxing Z, Zhong Q, Zhijun C. Tracheal intubation in patients with severe and critical COVID-19: Analysis of 18 cases. J Southern Med Uni 22020; 40 (03):337-341. doi: 10.12122/j.issn.1673-4254. 2020.03.07.

32. Hong L, Ysnqing G, Yuan W. Angel goes beside satan: The biphasic role of ACE2 on the susceptibility and virulence of severe acute respiratory syndrome coronavirus-2 and the potentially protective efficiency against acute lung injury. J Clin Cardiol (China). 2020; 3(5):400-5. dol. 10.13201/j.issn.1001-1439.2020.05.001.

33. Mandeep RM, Sapan SD, Frank R, Amit NP. Hydroxychloroquine or chloroquine with or without a macrolide for treatment of COVID-19: A multinational registry analysis. Lancet 2020; S0140-6736(20):31180-6. doi:10.1016/s01406736(20)31324-6.

34. Wang Y, Zhang D, Du G, Du R, Zhao J, Jin Y, et al. Remdesivir in adults with severe COVID-19: A randomised, doubleblind, placebo-controlled, multicentre trial. Lancet 2020; 395(10236): 1569-78. doi. 10.1016/S0140-6736(20) 31022-9.

35. Doggrell SA. Does lopinavir measure up in the treatment of COVID-19? Expert Opin Investig Drugs 2020; 1-4. doi: 10.1080/13543784.2020.1777277.

36. Antinori S, Cossu MV, Ridolfo AL, Rech R, Bonazzetti C, Pagani G, et al. Compassionate peramivir treatment of severe COVID-19 pneumonia in an intensive care unit (ICU) and Non-ICU patients: Clinical outcome and differences in post-treatment hospitalisation status. Pharmacol Res 2020; 158:104899. doi: 10.1016/j.phrs.2020.104899.

37. Zhong $\mathrm{H}$, Wang $\mathrm{Y}$, Zhang ZL, Liu YX, Le KJ, Cui M, et al.
Efficacy and safety of current therapeutic options for COVID-19 - lessons to be learned from SARS and MERS epidemic: A systematic review and meta-analysis. Pharmacol Res 2020; 157:104872. doi: 10.1016/j.phrs. 2020.104872.

38. Zhang Y, Xu Q, Sun Z, Zhou L. Currently targeted therapeutics against COVID-19: Based on the first-line experience in China. Pharmacol Res 2020; 157:104854 doi: 10.1016/ j.phrs.2020.104854.

39. Jhuma S, Nitin D, Kabra SK, Rakesh L. COVID-19 in children: Clinical approach and management. Ind J Ped 2020; 87(6):433-42. doi $\square 10.1007 /$ s12098-020-03292-1.

40. Cai Q, Yang M, Liu D, Chen J, Shu D, Xia J, et al. Experimental treatment with favipiravir for COVID-19: An openlabel control study. Engineering 2020; doi: 10.1016/ j.eng.2020.03.007.

41. Lisi D, Chunna L, Qi Z, Liu X, Li X, Zhang H, et al. Arbidol combined with $L P V / r$ versus $L P V / r$ alone against corona virus disease 2019: A Retrospective Cohort study. J Infec 2020; 81(1):e1-e5. doī10.1016/j.jinf.2020.03.002.

42. Zhen Z, Zhaohui L, Xu T, Chen C, Yang G, Zha T, et al. Arbidol monotherapy is superior to Lopinavir/ritonavir in treating COVID-19. J Infec 2020; 81(1):e21-3. doi: 10.1016/j.jinf.2020.03.060.

43. Pierce Williams RAM, Burd J, Felder L, Khoury R, Bernstein PS, Avila K, et al. Clinical course of severe and critical COVID-19 in hospitalised pregnancies: A U.S. cohort study. Am J Obstet Gynecol MFM 2020; 2(3):100134. doi: 10. 1016/j.ajogmf.2020.100134.

44. Ferrazzi E, Frigerio L, Savasi V, Vergani P, Prefumo F, Barresi S, et al. Vaginal delivery in SARS-CoV-2 infected pregnant women in northern Italy: A retrospective analysis. BJOG 2020; 10. doi: 10.1111/1471-0528.16278.

45. Yinying Z, Xiaozu L, Lu Z, Xiaojuan Y, Pin H, Ziyong Z. Safety management of hospital transport in critically III COVID-19 patients with extracorporeal membrane oxygenation combined with mechanical ventilation. Nurs Integ Tradit Chinese Western Med (China) 2020; 6(3):196-8. doi: 10.11997/nitcwm202003063.

46. Liu Xin, Shanlin X, Zhen J. Nursing experience of 5 critically III patients with COVID-19. Treated with noninvasive ventilator combined with prone position ventilation. Chinese Nurs Res (China) 2020; 34(08):1469-72. doi: 10. 12102/j. issn. 1009-6493. 2020. 08. 036.

47. Xueping S, Hongying Y, Fenhuan D, Ganying H. Nursing care of critically III COVID-19. Patients receiving noninvasive positive pressure ventilation. J Nurs Sci (China) 2020; 35(08):20-1. doi:10.3870/j.issn.1001-4152.2020.08.020. 